\title{
THEORETICAL CONCERNS IN APPLYING THE DIAGNOSIS OF PTSD TO PERSONS WITH HIV AND AIDS
}

\section{Ashraf Kagee}

Increasingly, mental health professionals, including psychologists, counsellors and social workers, are called upon to assist persons living with HIV to negotiate the mental health consequences of their condition. It has been suggested that serious mental health consequences following diagnosis with HIV are likely to occur and that developing countries may be "heading towards a mental health and social disaster" (Freeman, 2004). Freeman (2004) has identified various categories of persons affected by HIV who may experience psychological difficulties, including those recently diagnosed with HIV. Among recently diagnosed persons, it is thought that several psychiatric conditions may ensue, namely major depressive disorder (Gore-Felton, Koopman, Spiegel, Vosvick, Brondino \& Winningham, 2006), generalised anxiety disorder (Pence, Miller, Whetten, Eron \& GaGaynes, 2006) and posttraumatic stress disorder (Myers \& Durvasula, 1999; Martinez, Israelski, Walker \& Koopman, 2002; Olley, Zeier, Seedat \& Stein, 2005). This article examines some theoretical concerns regarding the viability of a diagnosis of PTSD for persons who have received a diagnosis of HIV in terms of its implications for mental health counselling.

By any account, a diagnosis with HIV is psychologically distressing, and newly diagnosed HIV-positive persons are likely to experience a range of social and emotional difficulties that stem from the knowledge that they have a life-threatening and contagious disease that will result in physical decline and death. In addition, stigma, discrimination and ostracism from friends, family and society in general may result in further emotional and psychological difficulties.

Posttraumatic stress disorder among HIV-infected persons has been the focus of some recent research. For example, among women attending HIV outpatient clinics in the United States, $42 \%$ were considered likely to meet the full criteria for PTSD and 22\% for partial PTSD (Martinez et al., 2002). The traumatic stressors in this study included violent events, sexual trauma, accidents, deaths and disasters (Martinez et al., 2002). The prevalence estimates found by Martinez et al. (2002) are much higher than those typically found in general community samples in the United States, which range between 4,6\% (Resnick, Kilpatrick, Dansky \& Saunders, 1993) and 5,1\% (Norris, 1992). Other studies of PTSD among HIV-positive persons have yielded varying prevalence estimates, depending on method of assessment. For example, $6 \%$ of newly infected South African patients attending immunology clinics had PTSD as determined by the Mini International Neuropsychiatric Interview (MINI) (Els, Boshoff, Scott, Strydom, Joubert \& Van der Ryst, 1999); 50\% among African American HIV-positive female sample had PTSD as assessed by the Composite International Diagnostic Inventory (CIDI) (Myers \& Durvasula, 1999); and 16\% among an American HIV-positive clinic sample had PTSD as measured by a PTSD Checklist (Leserman, Whetten, Lowe, Stangle, Swartz \& Hielman, 2005). Posttraumatic stress symptoms appear to be associated with disease progression among persons living with AIDS. For example, for every severely stressful life event per 6-month interval, the risk of early HIV disease progression doubled (Evans, Leserman, Perkins \& Stern, 1997). Symptoms of avoidance, which is a cluster of PTSD, have been shown to predict lower CD4 counts, which is a measure of disease progression (Lutgendorf, Antoni, Ironson, Klimas, Fletcher \& Schneiderman, 1997). 


\section{AIDS AS A TRAUMATIC STRESSOR}

The extent to which knowledge of being HIV positive provokes symptoms of trauma has been examined in a few studies. Indeed, a diagnosis of HIV has been described as a "potential trigger for PTSD" (Martinez et al., 2002:284). In a study of South African patients recently diagnosed with HIV and AIDS, Olley and colleagues found that $14,8 \%$ of their sample met the criteria for PTSD, of which $36 \%$ stated that the index trauma was knowledge of the diagnosis of HIV (Olley et al., 2005). Six months later the prevalence of PTSD was $20 \%$ among the same sample (Olley, Seedat \& Stein, 2006). In this longitudinal study PTSD was associated with longer duration of HIV infection and higher baseline total disability (Olley et al., 2006). In a study specifically aimed at investigating the psychological impact of HIV infection, $30 \%$ met the criteria for PTSD in response to their diagnosis (Kelly, Raphael, Judd, Perdices, Kernutt \& Burnett, 1998). These authors conclude that PTSD in response to HIV diagnosis has clinical validity and suggest that their data support the inclusion of the diagnosis of life-threatening illness as a traumatic incident that may lead to PTSD. It appears that there is a burgeoning line of research aimed at demonstrating that a diagnosis of HIV may be considered a traumatic stressor that precipitates a diagnosis of PTSD.

\section{THE EXPANDING DEFINITION OF A TRAUMA}

The tendency to categorise the experience of AIDS as a trauma is largely related to the shifting definition of a traumatic event. In terms of the Diagnostic and Statistical Manual of Mental Disorders ( $3^{\text {rd }}$ edition, revised), which is the diagnostic system used by many mental health professionals, for an event to be considered a traumatic stressor it was required to be "outside the bounds of everyday experience" and of sufficient magnitude to "provoke stress in nearly everyone" (APA, 1987). Thus experiences such as war, rape, torture or confinement to a concentration camp qualified as traumatic events, while everyday stressors did not (McNally, 2004). Following the publication of the DSM-IV (APA, 1994) and the DSM-IV-TR (APA, 2000), the concept of a traumatic stressor was broadened so that experiences such as "experiencing, witnessing, or being confronted with an event or events that involved actual or threatened death or serious injury were considered traumatic" (APA, 2000). This expansion of the A1 criterion permitted the inclusion of serious illnesses such as cancer and AIDS to be considered traumatic stressors. An important change in this shift from the DSM-III-R to the DSM-IV was the fact that the notion of a stressor was broadened to incorporate the person's emotional response in addition to the traumatic event, in the form of criterion A2 (McNally, 2004). This shift permitted various events that are not necessarily outside of ordinary human experience to be considered traumatic, including physical illness. In the spirit of such inclusivity, events such as hearing sexist jokes in the workplace (Avina \& O'Donohue, 2002), extra-marital affairs (Datillio, 2004) and watching a terrorist attack on television (Schuster, Stein, Jaycox, Collins, Marshall, Elliott, Zhou, Kanouse, Morrison \& Berry, 2001) have also been accepted as events that could potentially precipitate posttraumatic stress.

The broadening of the definition for a traumatic stressor has been referred to as "conceptual bracket creep" (McNally, 2003). McNally argues that conceptual bracket creep is a potentially serious nosological matter for several reasons. First, broadening the definition of a traumatic event reduces the likelihood of identifying the psychobiological mechanisms of PTSD, as both ordinary and canonical stressors are considered traumatic. Second, if the criterion for the stressor is broadened, its credibility as a cause of the disorder diminishes, as pre-existing vulnerability factors require greater emphasis. A related point is that a shift of the causal burden 
away from the stressor undercuts the very rationale for having a diagnosis of PTSD in the first place (McNally, 2003). Third, if most events qualify as traumatic stressors, then trauma becomes an all-purpose idiom of distress. Thus bracket creep serves to blur the distinction between traumatic stressors and ordinary stressors. In so doing it medicalises more of human experience, while simultaneously trivialising genuinely traumatic events (McNally, 2003). Fourth, bracket creep may render the established research data and clinical recommendations based on more restricted criteria inapplicable, i.e. it may impede the generalisation of new data to the populations in which the diagnostic criteria were originally developed. On the other hand, defining overly restrictive diagnostic criteria or limiting their clinical application in an arbitrary manner risks denying persons in need the benefit of relevant research and effective intervention (McNally, 2004).

In many developing countries the incidence of HIV has shown no sign of decreasing. In 2006 there were nearly 40 million people living with the disease and 3 million AIDS-related deaths worldwide (UNAIDS, 2006). Sub-Saharan Africa has the highest prevalence of the disease (Shisana, Rehle, Simbayi, Parker, Zuma, Bhana, Connolly, Jooste \& Pillay, 2005). It is estimated that in 2006 there were 24.7 million children and adults living with the disease in the region, with 2,8 million newly infected (UNAIDS, 2006). HIV prevalence is high in many subSaharan countries such as Botswana (37\%), Lesotho (28\%), Namibia (21\%), South Africa (21\%), Swaziland (38\%), Zimbabwe (24\%) (Worldmapper, 2007) In these countries many families have several members living with HIV. Thus it is likely that many persons who seek and receive an HIV test may anticipate a positive result, thus to some extent mitigating the shock potential of being diagnosed. The fact that a diagnosis with HIV may not be as shocking as is assumed to be the case challenges the notion of its traumatic nature, as the DSM criteria for PTSD require a response of "shock, horror and helplessness" (APA, 1994:428). Infection with HIV has unfortunately become a more or less common phenomenon on the Southern African landscape rather than a unique human phenomenon, as a trauma is considered to be in the DSM-IV. Furthermore, recent developments concerning the availability of antiretroviral treatment in South Africa mean that being HIV positive need not be thought of as being as lifethreatening as it was a decade ago. Persons with access to proper treatment may live for several decades and, with increasing numbers of people in developing countries receiving ART, more people are living with the condition (UNAIDS, 2006), thus adding to the perception of the normalcy of HIV, rather than its exceptionality.

To argue that an HIV-positive diagnosis may not warrant a diagnosis of posttraumatic stress disorder is not to deny its emotionally distressing nature. However, a response of distress to news of being HIV positive is to be contrasted with a psychiatric condition such as PTSD. While social support and supportive counselling may be indicated for emotional distress, best practice treatment for PTSD includes cognitive therapy (Hembree \& Foa, 2000) and antianxiety medication (Becker, Hertzberg, Moore, Dennis, Bukenya \& Beckham, 2007; Boehnlein \& Kinzie, 2007;). It is likely that most patients diagnosed with HIV require psychological and social support as well as assistance in coping with their condition. Some, as pointed out by Freeman, may also require mental health services, especially for conditions such as generalised anxiety disorder or major depressive disorder. Of course, trauma may result from AIDS-related stigma in that discriminatory acts such as violence or abuse that meet criteria A1 and A2 may provoke PTSD-related symptoms. However, such events are qualitatively different from the experience of receiving a diagnosis of HIV or living with AIDS. 


\section{CONCLUDING COMMENTS}

An acceptance that people do not respond passively to events, but instead engage with them in an active and problem-solving way suggests that a focus on the meaning that persons attribute to events and to stressful experiences is appropriate. Suffering and distress arise in a social context and as such are shaped by the meanings and understandings that people apply to events (Summerfield, 1999). The notion of traumatic memory as a fixed psychopathological phenomenon has only recently become salient in the discourse of suffering (Young, 1995). Whereas previously people in different contexts might have framed their experiences in religious, legal or ideological terms, in recent times such framing has been chiefly psychological, reflecting the dominance of a "Western trauma discourse" (Summerfield, 1999).

It has been suggested that emotional distress has been medicalised in Western culture and that this medicalisation has been inappropriately extended to human beings everywhere (Summerfield, 1999). Summerfield (1999) has argued that PTSD may be a pseudo-condition in many contexts. A conceptual paradigm based on the medicalisation of distress risks pathologising survivors by placing an emotional and social experience in the realm of psychopathology and medicine. In a chapter entitled "Cross-cultural perspectives on the medicalisation of human suffering" Summerfield (2004) argues that the salience of trauma in modern social discourse is related to an individualistically-minded version of personhood. He suggests that the binding properties of society have been lost in the modern era and that personal rights and a language of entitlement have instead assumed prominence. In such a social context, where personal injury, grievance and thus the need for restitution, are paramount, "situations that would formerly have been experienced as bad luck and the ordinary trials of life" (Summerfield, 2004:235) may be seen as traumatic.

Because of the role of poverty, stigma, gender violence, mother-to-child transmission, migrant labour and the controversial nature of treatment access in some countries, it is inappropriate to regard infection with HIV as an example of "bad luck or the ordinary trials of life". It is no accident that AIDS is much more prevalent in poor countries compared to wealthy nations. However, the argument in this article is that a case for the traumatic nature of AIDS may be misplaced. Persons diagnosed with HIV require help in coping with the psychological distress that ensues following diagnosis, living with their condition, accessing treatment and dealing with social stigma. Considering AIDS a traumatic stressor worthy of precipitating posttraumatic stress disorder may be an inappropriate way in which to frame what is likely to be in most cases non-pathological psychological distress. It is necessary for mental health practitioners, including social workers, psychologists and counsellors to consider the implications of this argument.

\section{REFERENCES}

APA (AMERICAN PSYCHIATRIC ASSOCIATION). 1987. Diagnostic and statistical manual of mental disorders (DSM-III-R) $\left(4^{\text {th }}\right.$ ed). Washington, DC: American Psychiatric Association.

APA (AMERICAN PSYCHIATRIC ASSOCIATION). 1994. Diagnostic and statistical manual of mental disorders (DSM-IV) $\left(4^{\text {th }} \mathrm{ed}\right)$. Washington, DC: American Psychiatric Association. 
APA (AMERICAN PSYCHIATRIC ASSOCIATION). 2000. Diagnostic and statistical manual of mental disorders (DSM-IV-TR). (4 ${ }^{\text {th }}$ ed, text revision). Washington, DC: American Psychiatric Association.

AVINA, C. \& O'DONOHUE, W. 2002. Sexual harassment and PTSD: is sexual harassment diagnosable trauma? Journal of Traumatic Stress, 15:69-75.

BECKER, M.E., HERTZBERG, M.A., MOORE, S.D., DENNIS, M.F., BUKENYA, D.S. \& BECKHAM, J.C. 2007. A placebo-controlled trial of bupropion SR in the treatment of chronic posttraumatic stress disorder. Journal of Clinical Psychopharmacology, 27:193-197.

BOEHNLEIN, J.K. \& KINZIE, J.D. 2007. Pharmacologic reduction of CNS noradrenergic activity in PTSD: the case for clonidine and prazosin. Journal of Psychiatric Practice, 13:7278.

ELS, C., BOSHOFF, W., SCOTT, C., STRYDOM, W., JOUBERT, G. \& VAN DER RYST, E. 1999. Psychiatric co-morbidity in South African HIV/AIDS patients. South African Medical Journal, 89(9):992-995.

EVANS, D.L., LESERMAN, J., PERKINS, D.O. \& STERN, R.A. 1997. Severe life stress as a predictor of early disease progression in HIV infection. American Journal of Psychiatry, 154:830-834.

FREEMAN, M. 2004. HIV in developing countries: eading towards a mental health and consequent social disaster? South African Journal of Psychology, 34:139-159.

GORE-FELTON, C., KOOPMAN, C., SPIEGEL, D., VOSVICK, M., BRONDINO, M. \& WINNINGHAM, A. 2006. Effects of quality of life and coping on depression among adults living with HIV/AIDS. Journal of Health Psychology, 11:711-729.

HEMBREE, E.A. \& FOA, E.B. 2000. Posttraumatic stress disorder: psychological factors and psychosocial interventions. Journal of Clinical Psychiatry, 61(7):33-39.

ISRAELSKI, D.M., PRENTISS, D.E., LUBEGA, S., BALMAS, G., GARCIA, P. \& MUHAMMAD, M. 2007. Psychiatric co-morbidity in vulnerable populations receiving primary care for HIV/AIDS. AIDS Care, 19(2):220-225.

KELLY, B., RAPHAEL, B., JUDD, F., PERDICES, M., KERNUTT, G. \& BURNETT, P. 1998. Posttraumatic stress disorder in response to HIV infection. General Hospital Psychiatry, 20(6):345-352.

LESERMAN, J., WHETTEN, K., LOWE, K., STANGLE, D., SWARTZ, M.S. \& THIELMAN, N.M. 2005. How trauma, recent stressful events, and PTSD affect functional health status and health utilization in HIV-infected patients in the south. Psychosomatic Medicine, 67(3):500-507.

LUTGENDORF, S.K., ANTONI, M.H., IRONSON, G., KLIMAS, N., FLETCHER, M.A. \& SCHNEIDERMAN, N. 1997. Cognitive processing style, mood, and immune function following HIV seropositivity notification. Cognitive Therapy and Research, 21:157-184.

MARTINEZ, A., ISRAELSKI, D., WALKER, C. \& KOOPMAN, C. 2002. Posttraumatic stress disorder in women attending human immunodeficiency virus outpatient clinics. Aids Patient Care and STDs, 16(6):283-291.

McNALLY, R.J. 2003. Progress and controversy in the study of posttraumatic stress disorder. Annual Review of Psychology, 54:229-252. 
McNALLY, R.J. 2004. Conceptual problems with the DSM-IV criteria for posttraumatic stress disorder. In: ROSEN, G.M. (ed) Posttraumatic stress disorder: issues and controversies. Chichester, UK: John Wiley \& Sons.

MYERS, H.F. \& DURVASULA, R.S. 1999. Psychiatric disorders in African American men and women living with HIV/AIDS. Cultural Diversity and Ethnic Minority Psychology, 5:249-262.

NORRIS, F.H. 1992. Epidemiology of trauma: frequency and impact of different potentially traumatic events on different demographic groups. Journal of Clinical and Consulting Psychology, 60:409-418.

OLLEY, B.O., ZEIER, M.D., SEEDAT, A. \& STEIN, D.J. 2005. Post-traumatic stress disorder among recently diagnosed patients with HIV/AIDS in South Africa. AIDS Care, 17:550-557.

OLLEY, B.O., SEEDAT, S., STEIN, D.J. 2006. Persistence of psychiatric disorders in a cohort of HIV/AIDS patients in South Africa: a 6-month follow-up study. Journal of Psychosomatic Research, 61:479-484.

PENCE, B.W., MILlER, W.C., WHETTEN, K., ERON, J.J. \& GAYNES, B.N. 2006. Prevalence of DSM-IV-Defined mood, anxiety, and substance use disorders in an HIV Clinic in the Southeastern United States. Journal of Acquired Immune Deficiency Syndromes, 42:298-306.

RESNICK, H.S., KILPATRICK, D.G., DANSKY, B.S. \& SAUNDERS, B.E. 1993. Prevalence of civilian trauma and posttraumatic stress disorder in a representative national sample of women. Journal of Consulting and Clinical Psychology, 61:984-991.

SCHUSTER, M.A., STEIN, B.D., JAYCOX, L.H., COLLINS, R.L. MARSHALL, G.N., ELLIOTT, M.N., ZHOU, A.J., KANOUSE, D.E., MORRISON, J.L. \& BERRY, S.H. 2001. A national survey of stress reactions after the September 11, 2001, terrorist attacks. The New England Journal of Medicine, 345:1507-1512.

SHISANA, O., REHLE, T., SIMBAYI, L.C., PARKER, W., ZUMA, K., BHANA, A., CONNOLly, C., JOOSTE, S. \& PILlAY, V. 2005. South African National HIV Prevalence, Incidence, Behaviour and Communication Survey. Cape Town: HSRC Press.

SUMMERFIELD, D. 1999. A critique of seven assumptions behind psychological trauma programmes in war-affected areas. Social Science \& Medicine, 48:1449-1462.

SUMMERFIELD, D. 2004. Cross-cultural perspectives on the medicalisation of human suffering. In: ROSEN, G.M. (ed) Posttraumatic stress disorder: issues and controversies. Chichester, UK: John Wiley \& Sons.

UNAIDS. 2006. AIDS epidemic update. Joint United Nations Programme on HIV and AIDS, World Health Organisation.

WORLDMAPPER. 2007. Available: http://www.sasi.group.shef.ac.uk /worldmapper/data/ nomap/227_worldmapper_data.xls. [Accessed: 19/03/2007].

YOUNG, A. 1995. The harmony of illusions: inventing post-traumatic stress disorder. Princeton, N.J.: Princeton University Press.

Prof Ashraf Kagee, Department of Psychology, Stellenbosch University, Stellenbosch, South Africa. 